\title{
Estimation of Pore Size of Porous Materials by Positron Annihilation Lifetime Measurement
}

\author{
Kenji ITO, Yasuhiro YAGI, Shingo HIRANO*, Masaru MIYAYAMA, Tetsuichi KUDO, \\ Akira KISHIMOTO* and Yusuke UJIHIRA \\ Graduate School of Engineering, The University of Tokyo, 7-3-1, Hongo, Bunkyo-ku, Tokyo 113-8656 \\ *Institute of Industrial Science, The University of Tokyo, 7-22-1, Roppongi, Minato-ku, Tokyo 106-8558
}

\author{
陽電子消滅寿命測定法による多孔質材料中の細孔の大きさや濃度の評価 \\ 伊藤賢志・八木康洋・平野晋吾* ·宮山 勝・工藤 徹一・岸本 昭* · 氏平祐輔 \\ 東京大学大学院工学系研究科, 113-8656 東京都文京区本郷 7-3-1 \\ *東京大学生産技術研究所, 106-8558 東京都港区六本木 7-22-1
}

\begin{abstract}
Pore size of several porous materials such as zeolites (MCM-41 and MCM-48) and highly fined grain aggregates of zirconia was estimated by means of positron annihilation lifetime measurement. Observed lifetimes of ortho-positronium (over $\sim 20 \mathrm{~ns}, \tau_{4}$ and $\tau_{5}$ ) correspond to the meso-pore sizes assessed by conventional porosimetries due to a nitrogen physisorption and a mercury porosimetry. The long-lived lifetime components included an unassigned lifetime component $\left(\tau_{5}\right)$, which was not detected by the other porosimetry. The observed ortho-positronium lifetimes are correlated to the mean size of pores. A relation between relative intensities of the long-lived ortho-positronium components $\left(I_{4}\right.$ and $\left.I_{5}\right)$ and specific surface areas is discussed and a variation of a numerical concentration of pores is correlated to the change of the particle sizes of the zirconia aggregates. [Received September 1, 1998; Accepted December 3, 1998]
\end{abstract}

Key-words : Porous material, Meso pore, Micro pore, Positronium, Positron annihilation, Pore size, Nondestructive analysis

\section{Introduction}

Various kinds of porous materials are utilized in science, engineering and industry. For example, zeolites are utilized as a molecular sieve, a nanoscopic reaction field of various chemical species or an inorganic ion exchanger, and porous glasses are used as filters, carrier of catalysts. A volume shrinkage phenomenon during a sintering of ceramic powders is attracting scientists of various fields. ${ }^{1)}$ Pore sizes of the porous materials are classified into three categories in IUPAC definition, micro pore (pore diameter: $0.8-2 \mathrm{~nm})$, meso pore $(2-50 \mathrm{~nm})$ and macro pore $(>\sim 50$ $\mathrm{nm})$.2) The meso-pore properties have been footlighted for developing functional materials because various functions of the porous materials are dependent on how they are controlled.

Pore size and size distribution are analyzed by gas physisorption method in general. Specified molecules are selected as a probe for the characterization of pores and the pore size is determined. As a supplemental porosimetry to the gas physisorption method, mercury porosimetry has been utilized to estimate the macro-pore size. However, above conventional porosimetries have certain shortcomings since an assumption of a pore shape is necessary to estimate the pore size, and a destruction of a pore structure is indispensable by a pressure and practical limits exist in a pre-treatment. Several techniques have been applied to the pore size estimation. Among them, small-angle X-ray scattering (SAXS), ${ }^{3)}$ small-angle neutron scattering (SANS) ${ }^{4)}$ and nuclear magnetic resonance (NMR) ${ }^{5)}$ are most promising techniques. An image processing by high-resolution transmission electron microscope (HR-TEM) is attempted to investigate the pore structure. ${ }^{6)}$ Recently, positron annihilation lifetime technique ${ }^{7}$ ) have been proved as a quite promising method to assess a pore size and its numerical concentration, since no practical method is available to estimate the micro- and/or meso-pore size nondestructively. An advantage of the method is to afford a direct informa- tion of the precise pore property. In addition, a positron is introduced even into a closed-pore, while the conventional porosimetries can evaluate only an open-pore.

Because of a positive-charge of a positron, the positron and an ortho-positronium (o-Ps: a bound state between a positron and an electron with parallel spins) tend to localize in low electron density spaces of materials. The positron is introduced into pore without a significant influence to a chemical and physical properties of a sample. Thus, one can obtain a precise information about the size and numerical concentration of free volume in polymer, void, pore and a surface in various solid materials through the analysis of an annihilation of positron and $o-\mathrm{Ps}$ in a sample. The pore size and numerical concentration are deduced from the lifetime and their relative intensity, respectively. A correlation between the Ps lifetime and the hole size ranging upto $\sim 0.6$ $\mathrm{nm}$ in radius, was reported, ${ }^{8), 9)}$ and it has been utilized in numerous studies on the free volume properties in polymers in last two decades. ${ }^{10)}$ Pore sizes over $\sim 1 \mathrm{~nm}$, much larger than the free volume, are able to be estimated from the lifetime of $o$-Ps by the decrease of its lifetime from its inherent lifetime, $142 \mathrm{~ns}$. A potentiality of the positron annihilation lifetime technique is discussed as a quantitative porosimetry for the bigger free spaces than $\sim 1 \mathrm{~nm}$ and is given in proceeding works. ${ }^{11), 12)}$

In the present work, results of the application of the positron annihilation lifetime measurement to the mesopore materials are described and a comparison of the results with those obtained by the nitrogen adsorption and the mercury porosimetries. The meso-pore size of zeolite, porous silica glass and fine grain aggregates of zirconia are estimated from a long-lived Ps lifetime component $\left(\tau_{4}\right.$ and $\tau_{5}$ ) over $20 \mathrm{~ns}$. The effectiveness of the positron annihilation lifetime technique for the investigation of the pore properties are demonstrated up to $\sim 30 \mathrm{~nm}$ in radius. 


\subsection{Sample preparations}

\section{Experimental section}

Zeolites: MCM-41 and MCM-48 were synthesized by the hydrothermal reaction, and were used after washing, drying and fired. ${ }^{13)}$ Nitrogen physisorption isotherms of the MCM-41 and -48 were characteristic of mesoporous materials with a BET surface area above $1500 \mathrm{~m}^{2} / \mathrm{g}$ and with a uniform pore radius of $1.26 \mathrm{~nm}$ and $1.37 \mathrm{~nm}$, respectively. Two kinds of the zeolite powders were pelletted by pressing at $49 \mathrm{MPa}$ to prepare the sample pellets of $1 \mathrm{~cm}$ in diameter and $\sim 1.5 \mathrm{~mm}$ in thickness. Other characters of the samples were shown in Table 1.

Zirconia and its derivatives: Highly fine grained aggregates of zirconia (FZ) were prepared by a hydrolysis method. Yttria-stabilized zirconia (YSZ) containing 2 (for

Table 1. Characteristic Pore Parameters of Zeolite

the 2YSZ), 3 (3YSZ) and 8 (8YSZ) molar percentage of yttria were supplied from Tosoh Corp. and used in the present experiments. Two grams powders of YSZ's were pressed at $49 \mathrm{MPa}$ uniaxially to obtain green compact pellets (1 $\mathrm{cm}^{2} \times 2 \mathrm{~mm}$ ). Pore properties and other characteristics of the prepared samples were listed in Table 2.

\subsection{Positron annihilation lifetime measurement}

Decay curves of positron annihilations were observed with a conventional fast-fast coincident system with a time resolution less than $\sim 350$ ps FWHM (full width at half maximum). ${ }^{14)}$ The lifetime measurement was carried out with several time scales in a range from $0.035 \mathrm{~ns} / \mathrm{ch}$ to $\sim 0.900 \mathrm{~ns} / \mathrm{ch}$ in order to obtain a complete decay curves of annihilation and data points for the precise analysis. All measurements were carried at room temperature. The positron source was $7.5 \times 10^{-5} \mathrm{~Bq}^{22} \mathrm{NaCl}$ contained in Kapton foils with a thickness of $7.5 \mu \mathrm{m}$. An error caused by a positron annihilation in the sealing films of ${ }^{22} \mathrm{NaCl}$ was subtracted at the computer fitting step. The positron source was sandwiched between the two sample pellets. The sandwiched source was kept under a vacuum of $\sim 0.13 \mathrm{~Pa}$ throughout the measurement so that the effect of oxygen in the decay curves may be negligible. Typical results of the positron annihilation decay curves for the zeolite and the zirconia were shown in Fig. 1. Obtained decay curves with total counts of $8 \times 10^{6}$ were analyzed by the computer programs PATFIT-88 ${ }^{15)}$ with a good statistical precision and resolved into four or five lifetime components.

\subsection{Principle of positron annihilation}

In the positron annihilation lifetime technique, the positron is used as a probe. A positron density is highest at an interstitial region among atoms and in vacancy in a material because the positron is repelled from positively charged ion cores of atoms. Therefore, the positron is highly localized in open spaces such as defect, vacancy, vacancy cluster, free volume in polymer, void and pore. When the positron is trapped in an open space, its annihilation rate, $\lambda$, is equal to the reciprocal of the positron lifetime $(\tau)$, and expressed by an overlap integral of an electron and the positron densities $\left(\rho^{-}, \rho^{+}\right)$on the site: ${ }^{7), 16)}$

$$
\lambda=\pi r_{0}^{2} c \iiint \rho^{-}(\mathrm{r}) \rho^{+}(\mathrm{r}) \mathrm{d} r
$$

where, $\gamma_{0}$ is the classical electron radius and $c$ is the velocity of light. This equation indicates that the lower the average electron density, the larger the hole size.

\begin{tabular}{|c|c|c|c|c|}
\hline $\begin{array}{l}\text { B.E.T. specific suface area } \\
\qquad S\left(\mathrm{~m}^{2} / \mathrm{g}\right)\end{array}$ & 185.4 & 16.5 & 15.3 & 13.3 \\
\hline $\begin{array}{l}\text { mean density } \\
\rho \quad\left(\mathrm{g} / \mathrm{cm}^{3}\right)\end{array}$ & 1.74 & 2.47 & 2.47 & 2.47 \\
\hline $\begin{array}{l}\text { mean particle size* } \\
\qquad L \quad(\mathrm{~nm})\end{array}$ & 9.60 & 70.2 & 79.4 & 91.3 \\
\hline $\begin{array}{c}\text { porosity } \\
v_{p} \quad\left(\mathrm{~cm}^{3} / \mathrm{g}\right)\end{array}$ & 0.1394 & 0.2227 & 0.2155 & 0.2065 \\
\hline $\begin{array}{l}\text { pore radius } \\
R \quad(\mathrm{~nm})\end{array}$ & 1.91 & $25.3^{* *}$ & $27.9^{* *}$ & $33.4^{* *}$ \\
\hline
\end{tabular}

\footnotetext{
* Values were estimated according to the equation, $L=3 / \rho S$, based on the theory of Plank and Drake. ${ }^{29)}{ }^{* *}$ Pore radii were determined by mercury porosimetry.
}

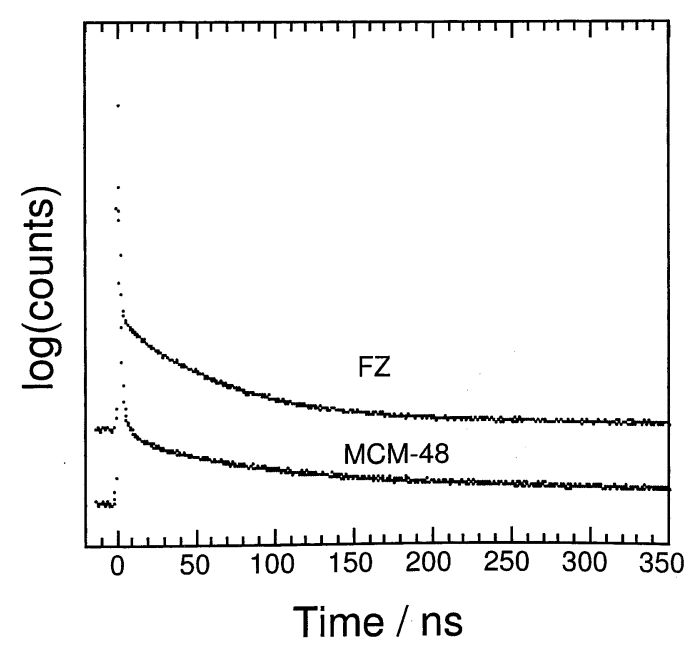

Fig. 1. Decay curves of positron annihilation for MCM-48 and FZ. Measurements were performed under $\sim 0.13 \mathrm{~Pa}$ at room temperature. 
The other probe, or $o$-Ps is produced in the process of positron annihilation in a lower electric conductive or insulated materials. Ps's are classified into two species in terms of spin directions between the positron and the electron. Ortho-Ps (o-Ps: a triplet state) has a parallel spin state, whereas para-Ps ( $p$-Ps: a singlet state) has a antiparallel state. Because $o$-Ps has a relatively longer lifetime (142 ns in vacuum), a larger hole can be detected whereas the positron generally detect a smaller free space less than 0.1-0.2 nm ( $500 \mathrm{ps})$. Good correlations have been found between an $o$-Ps lifetime and various free volume hole or pore sizes in several porous materials, ${ }^{17)}$ and the free volume computed from velocity of sound. ${ }^{18)}$ The free volume sizes in polymers observed by the $o$-Ps lifetimes normally range up to $\sim 0.6 \mathrm{~nm}$ in radius. Extra longer Ps lifetimes over $\sim 20 \mathrm{~ns}$ are also observed in several oxides which have a mesoscopic hole size. Qualitative correlations between the Ps lifetime and the hole size in this region are discussed elsewhere. ${ }^{11), 12)}$

A formation probability of $o$-Ps is controlled by free volume hole and pore concentrations and a specific surface area of materials. ${ }^{19)}$ The formation probability is represented by a relative intensity $(I)$ of $o$-Ps obtained through a data analysis. "Escape probability" of the $o$-Ps is defined by a ratio of the relative intensity of the $o$-Ps annihilating in the pore to that in the bulk. This parameter is also indicated as a measure of the specific surface area. ${ }^{19}$ The relation means that $o$-Ps will provide a specific surface area. The possibility is endorsed by the valid correlation found for silica gel by Chuang and $\mathrm{Tao}^{20}$ ) for zeolite by Ito et $\mathrm{al.}^{21)}$ and for polymer resin by Venkateswaran et al. ${ }^{12}$

2.4 Data analysis

In the finite term analysis by using the RESOLUTIONFIT and the POSITRONFIT program in the PATFIT-88 package, ${ }^{15)}$ the decay curves are expressed as,

$$
\begin{aligned}
& y(t)=R(t)^{*}\left(N_{\mathrm{t}} C(t)+B\right) \\
& C(t)=\sum_{i=1}^{n} \alpha_{i} \lambda_{i} e^{-\lambda_{i} t}
\end{aligned}
$$

where, $y(t), R(t), N_{\mathrm{t}}, C(t)$ and $B$ represent an observed decay curve, an instrumental time-resolution function, a numerical normalization factor, a distribution of a time difference pulse and a background, respectively. $\alpha_{i}$ and $\lambda_{i}$ are a normalized intensity and an annihilation rate of $i$-th component, respectively. The term number of a minimized solution, $i$, is determined for obtaining a best fitting parameter (variance of the fit : 1.1-1.3). Average lifetimes, $\tau_{i}$, is defined by reciprocal $\lambda_{i}$. Their relative intensities, $I_{i}$, are obtained from the finite term analysis. The shortest component $\left(\tau_{1}: 125-200 \mathrm{ps}\right)$ is a mean lifetimes due to a self-annihilation of para-positronium ( $p$-Ps) and a free annihilation with an electron belonging to atoms in a bulk. The second shortest component ( $\tau_{2}: 200-500 \mathrm{ps}$ ) is attributed to an annihilation of positrons at a free space such as atomic vacancy, vacancy cluster, void and free volume. The third component $\left(\tau_{3}: 1-10 \mathrm{~ns}\right)$ is associated with a "pick-off" reaction of $o$-Ps at free volumes of polymers and its analogy. A subthird component $\left(\tau_{3 \mathrm{a}}: 0.8-1 \mathrm{~ns}\right)$ is sometimes observed in materials which have a partially periodic structure. Long-lived components, $\tau_{4}$ and $\tau_{5}$, are observed in mesoporous materials. The components are observed due to an annihilation of $o$-Ps at a larger free space such as grain boundary, cylindrical pore and regions surrounded by secondary particles.

\section{Results and discussion}

\subsection{0 -Ps lifetime in meso-pores}

Long-lived lifetimes of $o$-Ps over $20 \mathrm{~ns}\left(\tau_{4}\right.$ and $\left.\tau_{5}\right)$ are observed in two kinds of zeolites and the zirconia ag- gregates measured. We mainly discussed annihilation lifetimes and relative intensities of $o$-Ps focussing on the $\tau_{4}$ and $\tau_{5}$ components.

Zeolite Positron annihilation lifetime data for the MCM-41 and -48 are listed in Table. 3. Cavity radii for the MCM-41 and -48 are calculated as $0.43 \mathrm{~nm}$ and $0.45 \mathrm{~nm}$ from the obtained 3rd lifetimes $\left(\tau_{3}\right), 4.12 \mathrm{~ns}$ and $4.42 \mathrm{~ns}$, respectively, by applying the expression given by Nakanishi et al.,8)

$$
\tau=0.5\left[1-\frac{R}{R+0.166}+\frac{1}{2 \pi} \sin \left(\frac{2 \pi R}{R+0.166}\right)\right]^{-1}
$$

where, $\tau$ (in $\mathrm{ns}$ ) and $R$ (in $\mathrm{nm}$ ) are a Ps lifetime and a cavity radius, respectively. For the convenience of a comparison of $\tau_{2}$ and $\tau_{3 \mathrm{a}}$ between the MCM-41 and the MCM-48, averaged $\tau_{2}$ component of MCM-48 was deconvoluted to $\tau_{1}$ and $\tau_{3 \mathrm{a}}$ components assuming that a set of $\tau_{1}$ and $\tau_{3 \mathrm{a}}$ and the ratio of $I_{1}$ to $I_{3 \mathrm{a}}$ were similar to those of the MCM-41. The results were shown in parentheses in Table. 3 . The presence of smaller pore has not been reported for the MCM system, ${ }^{13)}$ the $\tau_{3}$ component may not be attributed to $\alpha$-cage of micro-porous zeolites, theoretical radius ranging from $0.3 \mathrm{~nm}$ to $0.6 \mathrm{~nm}$. The appearance of the $\tau_{3}$ component in the MCM-41 and the MCM-48 is expected to be due to

\begin{tabular}{|c|c|c|c|}
\hline & & MCM-41 & MCM-48 \\
\hline \multirow{2}{*}{$\tau_{1}$ comp. } & $\tau_{1}, \mathrm{~ns}$ & 0.119 & $(0.120)^{* c}$ \\
\hline & $I_{1}, \%$ & 21.7 & $(36.1)^{* c}$ \\
\hline \multirow{2}{*}{$\tau_{2}$ comp. } & $\tau_{2}, \mathrm{~ns}$ & $(0.554)^{* a}$ & 0.509 \\
\hline & $I_{2}, \%$ & $(47.0)^{* b}$ & 69.4 \\
\hline \multirow{2}{*}{$\tau_{3 \mathrm{a}}$ comp. } & $\tau_{3 \mathrm{a}}, \mathrm{ns}$ & 0.927 & $(0.930)^{* c}$ \\
\hline & $I_{3 a}, \%$ & 25.3 & $(33.3)^{* c}$ \\
\hline \multirow{2}{*}{$\tau_{3 \mathrm{~b}}$ comp } & $\tau_{3 \mathrm{~b}}, \mathrm{~ns}$ & 4.14 & 4.42 \\
\hline & $I_{3 \mathrm{~b}}, \%$ & 47.1 & 4.13 \\
\hline \multirow{2}{*}{$\tau_{4}$ comp. } & $\tau_{4}, \mathrm{~ns}$ & 37.7 & 26.9 \\
\hline & $I_{4}, \%$ & 3.59 & 2.32 \\
\hline \multirow{2}{*}{$\tau_{5}$ comp. } & $\tau_{5}, \mathrm{~ns}$ & 129.0 & 89.2 \\
\hline & $I_{5}, \%$ & 2.35 & 24.2 \\
\hline
\end{tabular}

Table 3. Results of Positron Annihilation Measurement for Zeolite

$* a \tau_{2}$ is a mean value between $\tau_{1}$ and $\tau_{3 \mathrm{a}}$. $* b I_{2}=I_{1}+I_{3 \mathrm{a}}$. $* c$ These values were determined by a ratio of $\tau_{1}$ component to $\tau_{3 \mathrm{a}}$ component of MCM-41. 
voids at silica walls. The 4 th component $\left(\tau_{4}\right)$ has lifetimes of 37.7 and $26.9 \mathrm{~ns}$ for MCM-41 and -48 , respectively. These components are attributable to the meso pores with 1.37 and $1.26 \mathrm{~nm}$ in radius given from the nitrogen adsorption measurement. The 5 th component $\left(\tau_{5}\right)$ is observed for both samples, although a peak due to $\tau_{5}$ component is not detected by the nitrogen physisorption method. Obtained lifetimes indicate the presence of very large pores $(>\sim 7$ $\mathrm{nm}$ in radius). ${ }^{22)}$ Very long-lived lifetimes appeared in $13 \mathrm{X}$ and SK-40 zeolites ${ }^{11)}$ were predicted to correspond to a grain boundary or a macro cavity in the porous materials. We speculate that the $\tau_{5}$ component may be due to the higher order structure with pore size of around $30 \mathrm{~nm}$ detected by the nitrogen physisorption in the MCM proposed by $\mathrm{Wu}$ et al., ${ }^{23)}$ although similar pore sizes have not reproduced in this study.

Aggregates of zirconia (FZ) and yittria-stabilized zirconia compounds (YSZ)

Observed decay curves of the positrons annihilation containing $\tau_{4}$ and $\tau_{5}$ components for the $\mathrm{FZ}$ and for the 2-3- and $8 Y S Z$ 's were processed and the results are shown in Table 4 . The $\tau_{4}$ component can be attributed to the pore detected by the nitrogen adsorption or the mercury porosimetry. The $\tau_{4}$ increases as an increase in the pore size. The $\tau_{5}$ component $(\sim 88 \mathrm{~ns})$ appeared for the FZ. A differential peak of the nitrogen physisorptiometry due to the bigger pore being attributable to the $\tau_{5}$ component is not observed. According to the study by Gol'danskii et al., ${ }^{22)}$ an $o$-Ps lifetime of $\sim 88 \mathrm{~ns}$ could be attributed to a pore size of $\sim 14 \mathrm{~nm}$ in diameter. A mean particle size can be estimated from the density and the specific surface area data based on the theory of Plank and Drake (see Table 2). The correlation study between the pore size and the mean particle size for the FZ, 2YSZ, 3YSZ and 8YSZ leads to the conclusion that a particle size of $46.8 \mathrm{~nm}$ in diameter is correspond to a pore size of $\sim 14 \mathrm{~nm}$ in diameter deduced from Fig. 2. This implies the presence of a secondary parti-

Table 4. Results of Positron Annihilation Measurement for Zirconia

FZ 2YSZ 3YSZ 8YSZ

\begin{tabular}{cccccc}
\hline & & & & & \\
$\tau_{1}$ comp. & $\tau_{1}, \mathrm{~ns}$ & 0.129 & 0.199 & 0.183 & 0.186 \\
& $I_{1}, \%$ & 75.9 & 70.3 & 86.6 & 89.8 \\
& & & & & \\
$\tau_{2}$ comp. & $\tau_{2}, \mathrm{~ns}$ & 0.853 & 0.452 & 0.542 & 0.550 \\
& $I_{2}, \%$ & 5.55 & 24.1 & 10.1 & 8.05 \\
& & & & & \\
& & & & & \\
$\tau_{3}$ comp. & $\tau_{3}, \mathrm{~ns}$ & 9.36 & 2.80 & 3.06 & 3.85 \\
& $I_{3}, \%$ & 0.740 & 1.21 & 0.486 & 0.359 \\
& & & & & \\
& & & & & \\
$\tau_{4}$ comp. & $\tau_{4}, \mathrm{~ns}$ & 33.6 & 122.7 & 128.0 & 130.2 \\
& $I_{4}, \%$ & 10.2 & 4.38 & 2.81 & 1.76 \\
& & & & & \\
$\tau_{5}$ comp. & $\tau_{5}, \mathrm{~ns}$ & 88.3 & - & - & - \\
& $I_{5}, \%$ & 7.69 & - & - & - \\
\hline
\end{tabular}

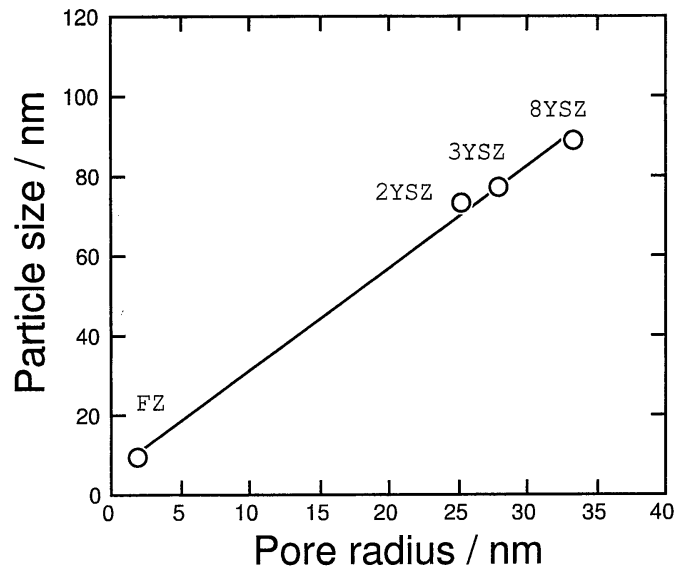

Fig. 2. Relation between pore radii and primary particle sizes for the zirconia aggregates. The primary particle sizes were determined from the apparent bulk density and the specific surface area (see Table 2).

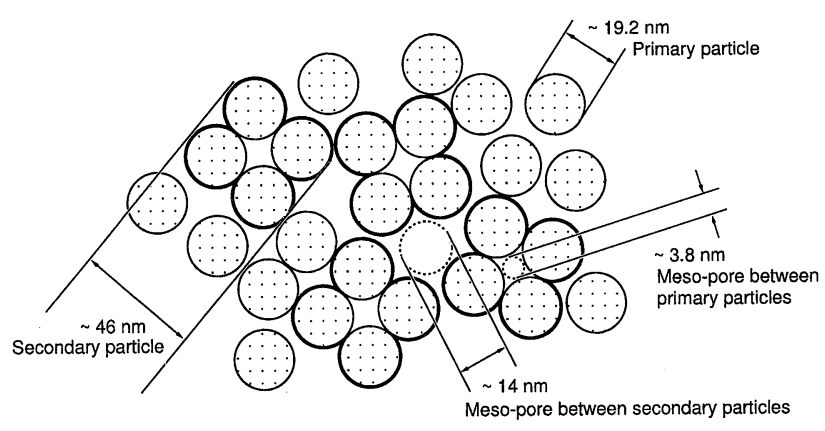

Scheme 1. Illustration of higher order aggregation model for the FZ.

cle due to the primary particles (19.2 $\mathrm{nm}$ in diameter) of 14.5 units. Therefore, the $\tau_{5}$ component for the $\mathrm{FZ}$ may be attributed to the annihilation of $o$-Ps in a larger pore formed among the secondary particles. The aggregation model was illustrated in Scheme 1.

A surfase area of a $j$-th particle is estimated by $S_{j}=\pi D_{j}^{2}$, where $D_{j}$ represents a diameter, under an approximation of a spherical particle. A surface area inside the secondary particle, i.e., an internal surface area formed in the aggregates of the primary particle, is deduced as $S_{\text {in }}=14.5 \times$ $S_{1}-S_{2}$. A ratio of $S_{\text {in }}$ to $S_{2}$ is calculated to $\sim 1.5$. As described above, the $o$-Ps yields of the long-lived components $\left(\tau_{4}\right.$ and $\tau_{5}$ ) are dependent on the surface area of the porous material. A ratio of $I_{4}$ to $I_{5}$ for the $\mathrm{FZ}$ equals $\sim 1.3$. The agreement between these values suggests the valid formation of the secondary particles and the formation of the voids inside the secondary particles.

A paper is reported on a relation between a macroscopic volume shrinkage and a pore behavior during a sintering process of a yttria-doped zirconia studied by means of the positron annihilation lifetime technique. ${ }^{24)}$ The results showed the decrease of intensity $\left(I_{4}\right)$ and a pore concentration during the sintering process. These results suggest that the information obtained by the positron annihilation is quite effective for the analysis of the mesoscopic structure during the thermo-mechanical process.

3.2 Relation between Ps lifetime and pore size

Figure 3 shows a relation between the obtained long-lived Ps lifetimes $\left(\tau_{4}\right.$ and $\left.\tau_{5}\right)$ and the corresponding pore radii, together with a Ps lifetime of a porous glass. ${ }^{*}$ The relation 


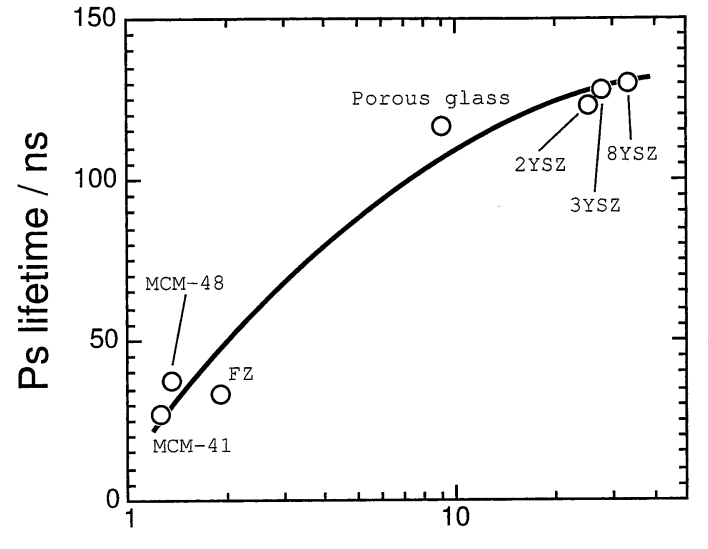

Radius / nm

Fig. 3. Relation between long-lived lifetime of positronium ( $\tau_{4}$ and $\tau_{5}$ ) and pore radius for the several materials. Solid line is guide to the eye.

exhibits a clear correlation between the Ps lifetime and the pore radius in a mesoscopic region. The present result implies that the correlation holds for much longer lifetimes up to $\sim 140 \mathrm{~ns}$, even though some studies have reported the correlation between Ps lifetimes and pore sizes hold up to $\sim 90$ ns in the previous literatures. ${ }^{11), 12)}$ From the present results, the relation between Ps lifetime and pore size is proved to be applicable to the characterization of alumina, silica and zirconia powders. This shows a potentiality of positron annihilation technique as a novel non-destructive porosimetry for the inorganic powders and ceramics. The correlation could become a basis of a routine analysis. Although quantum mechanical approaches have been attempted in order to give a theoretical basis to the relationship, ${ }^{25), 26)}$ a satisfactory analytical expression between the lifetime and the pore size have not been established for the practical analysis. We are continuing a discussion in this line by using a more refined model for presenting a universal curve between lifetime of Ps and pore radius. ${ }^{27)}$

\section{Conclusion}

Advantages and possibility of measuring a pore size in the mesoscopic range by the positron annihilation lifetime technique were demonstrated. Correlation between the meso-pore size of the zeolites and the zirconia compounds and the long-lived Ps lifetime components $\left(\tau_{4}\right.$ and $\left.\tau_{5}\right)$ were examined. The observed long-lived Ps lifetimes correspond to pore sizes obtained by conventional porosimetry using the nitrogen physisorption and the mercury porosimetry. Moreover, different lifetime components were detected which did not appear by the nitrogen physisorption measurement of the zeolites and the zirconia derivatives. The observed pore sizes are over $\sim 7 \mathrm{~nm}$ for the zeolites and the FZ. The pore size observation revealed the presence of the higher order structure, and the formation of free spaces through the secondary particles aggregation. The ratio of $I_{4}$ to $I_{5}$ confirmed the validity of our conclusion. The observed Ps lifetimes are significantly correlated to those obtained by the conventional porosimetries. The result suggests that the positron annihilation lifetime technique is an effective mean for the investigation of the pore properties even in a relatively bigger pores up to $\sim 30 \mathrm{~nm}$ in radius.

* Porous silica glass was supplied from Kokonoe Co., Ltd. in Nara Prefecture. Pore radius was determined to $9.11 \mathrm{~nm}$ by the marcury porosimetry.
Acknowledgment The authors were grateful to Prof. Takashi Tatsumi (The University of Tokyo) for the preparation of zeolites (MCM-41 and -48) and the fruitful discussion.

\section{References}

1) For example, A. Roosen and H. Hausner, "Advances in Ceramics, Vol. 2, Science and Technology of Zirconia II," Ed. by N. Claussen, M. Rühle and A. Heuer, Am. Ceram. Soc., Columbus, OH (1984) pp. 714-26.

2) IUPAC Manual of Symbols and Terminology, Appendix 2 , Part 1, Colloid and Surface Chemistry, Pure Appl. Chem., 31, 578 (1972).

3) N. Setoyama, M. Ruike, T. Kasu, T. Suzuki and K. Kaneko, Langmuir, 9, 2612-17 (1993).

4) P. G. Hall and R. T. Williams, J. Colloid Interfa. Sci., 104, 151-74 (1985).

5) D. P. Gallegos, K. Munn, D. M. Smith and D. L. Stermer, J. Colloid Interfa. Sci., 119, 127-40 (1987).

6) M. Endo, K. Nishimura, T. Ishibe, M. Ueda and A. Miyashita, 10th Fall Meeting of The Ceramic Society of Japan, Nagano, Japan, Oct. (1997) p. 352.

7) Y. C. Jean and D. M. Schrader, "Positron and Positronium Chemistry,” Elsevier, Amsterdam (1988).

8) H. Nakanishi, S. J. Wang and Y. C. Jean, "Positron Annihilation Studies of Fluids," Ed. by S. C. Sharma, World Scientific, Singapore (1988) pp. 292-98.

9) O. E. Mogensen, "Positron and Positronium Chemistry," Springer-Verlag, Berlin (1995) pp. 54-61.

10) For example see, Y. Ujihira, M. Tanaka and Y. C. Jean, Radioisotopes, 42, 43-56 (1993); S. J. Wang, C. L. Wang and B. Wang, J. Radioanal. Nucl. Chem., Articles, 210, 40721 (1996).

11) H. Nakanishi and Y. Ujihira, J. Phys. Chem., 86, 4446-50 (1982).

12) K. Venkateswaran, K. L. Cheng and Y. C. Jean, J. Phys. Chem., 88, 2465-69 (1984).

13) (a) K. A. Koyano, T. Tatsumi, Y. Tanaka and S. Nakata, J. Phys. Chem., B, 101, 9436-40 (1997); (b) T. Tatsumi, K. A. Koyano, Y. Tanaka and S. Nakata, Chem. Lett., 469-70 (1997); (c) J. S. Beck. J. C. Vartuli, W. J. Roth, M. E. Leonowicz, C. T. Kresge, K. D. Schmitt, C. T.-W. Chu, D. H. Olson, E. W. Sheppard, S. B. McCullen, J. B. Higgins and J. L. Schlenker, J. Am. Chem. Soc., 114, 10834-43 (1992).

14) N. Furusaki, Y. Ohko and Y. Ujihira, Kobunshi Ronbunsyu, 50, 969-75 (1993).

15) P. Kirkegaard, N. J. Pederson and M. Eldrap, PATFIT-88: A Data-Proccesing System for Positron Annihilation Spectra on Mainframe and Personal Computers, Tech. Rep. Risø-M2740, Risø National Laboratory, DK-4000 Roskilde, Denmark 1989.

16) R. W. Siegel, Ann. Rev. Mater. Sci., 10, 393-425 (1980).

17) Y. Kobayashi, K. Haraya, Y. Kamiya and S. Hattori, Bull. Chem. Soc. Jpn., 65, 160-63 (1992).

18) Y. Ujihira, T. Ryuo, Y. Kobayashi and T. Nomizu, Appl. Phys., 16, 71-74 (1987)

19) W. Brandt and R. Paulin, Phys. Rev. Letters, 21, 193-95 (1968).

20) S. Y. Chuang and S. J. Tao, Chem. Phys., 54, 4902-07 (1971).

21) Y. Ito, T. Yamashina and M. Nagasaka, Appl. Phys., 6, 32326 (1975)

22) V. I. Gol'danskii, B. M. Levin, A. D. Mokrushin, M. A. Kaliko and M. N. Pervushina, Dokl. Akad. Nauk SSSR, 191, 85558 (1970).

23) C. N. Wu, T. S. Tsai, C. N. Liao and K. J. Chao, Microporous Mater., 7, 173-85 (1996).

24) Y. Yagi, S. Hirano, M. Miyayama and Y. Ujihira, Mater. Sci. Forum, 255-257, 433-35 (1997).

25) V. P. Shantarovich, Yu. P. Yampolskii and I. B. Kevdina, Khim. Vysokikh Energii, 28, 53-59 (1994).

26) T. Goworek, K. Ciesielski, B. Jasińska and J. Wawryszczuk, Materials Sci. Forum, 255-257, 296-98 (1997).

27) K. Ito, H. Nakanishi and Y. Ujihira, Radioisotopes, 47, 20611 (1998).

28) D. Dollimore and G. R. Heal, J. Appl. Chem., 14, 109-14 (1964).

29) C. J. Plank and L. C. Drake, J. Colloid Sci., 2, 399-412 (1947). 